\title{
A thermographic method to evaluate laminar bubble phenomena on airfoil operating at low Reynolds number
}

\author{
by G. Cesini ${ }^{1}$, R. Ricci' ${ }^{2}$, S. Montelpare ${ }^{1}$, E. Silvi ${ }^{1}$ \\ (1) Università di Ancona, Dipartimento di Energetica, Italy \\ (2) Università "G.D’Annunzio" di Chieti, D.S.S.A.R.R., Italy.
}

\begin{abstract}
The aim of this research is the study of the laminar boundary layer separation phenomena on aerodynamic bodies by infrared thermography. The presence and the size of laminar bubble are mainly observed. A thermographic method is adjusted to detect the presence and the longitudinal dimension of the laminar bubble. In this region the convective heat transfer coefficient is lower than in the surroundings, because of the recirculating flow. Heating the airfoil surface, the laminar bubble will appear warmer than the other zones and so it is possible to know its presence and position.
\end{abstract}

\section{Introduction}

Laminar separation bubbles are caused by the presence of the adverse streamwise pressure gradient in the boundary layer flow field. When separation occurs the disturbances in the shear layer are amplified and a transition to turbulence may develop. In this condition the shear layer may reattach on the body surface generating a so called Laminar Separation Bubble (LSB), see Fig.1.

Separation bubbles are common in several engineering applications, e.g. low Reynolds number airfoils, turbine blades, ecc... where their presence can increase dramatically the body pressure drag. An extensive literature is available to understand the bubble behaviour and many numerical studies have been carried out but a systematic analysis regarding low Reynolds number airfoils is actually limited, owing to the difficulties to experimentally investigate the phenomenon.

Three characteristic points distinguish the LSB: separation point, transition point and the turbulent reattachment point. The streamwise position of the separation point may be find by the investigation of the 'similar' solution of the laminar boundary layer equation introducing the Falkner-Skan equation [1], or by approximate methods based on the integral approach at the boundary layer problem [2].

Two flow regions are present in the separated flow: a shear layer and a recirculating zone; the transition of the shear layer is normally studied by the Orr-Sommerfeld stability equation, since this equation is based on a linear approach only the first instability point is carried out. The distance between the separation and transition points is based so on some experimentally suggested criterions. Horton [3] and Van Ingen [4] results have been extensively used. Actually the $e^{n}$ criterion [5-6] seems more suitable for airfoil applications.

The turbulent reattachment point is generally obtained using the skin-friction and velocity profile formulas of Swafford [7].

More recent studies [8-12] point out the difficulties to study the LSB because of the unsteadiness of the phenomenon and the dependence on the spectral components of the main flow turbulence. In the present work, IR thermography is proposed as a quantitative experimental technique to determine the three characteristic points of the LSB by analyzing the surface heat transfer coefficient with the heated-thin-foil technique [13]. A comparison with numerical and analytical results, obtained by the applications of the previous discussed criteria, are presented for the tested airfoil. 


\section{Experimental set-up}

The experimental apparatus used for this research is composed by a subsonic wind tunnel with the following characteristics:

- open circuit and closed section

- average turbulence factor on the main flow: $0.30 \%$

- overall dimensions of the test section: $620(\mathrm{~W}) \times 380(\mathrm{H}) \times 1500(\mathrm{~L}) \mathrm{mm}$.

- maximum velocity: $38 \mathrm{~m} / \mathrm{s}$

- contraction ratio: 4.65

- fan electrical power: $5.5 \mathrm{~kW}$

In previous works [14] the aerodynamic performances of the wind tunnel have been evaluated on an Eppler 387 airfoil by comparing the results with data provided by the Stuttgart Universitat and Princeton University. The comparison shows a good agreement.

In this work the aerodynamic measurements of a thin airfoil, the RR3823HL, are presented. The measurements are compared with the thermographic investigations provided by a FLIR SC3000 LW infrared camera. Finally a comparison with numerical results, carried out by analytical study and numerical investigations, obtained by XFOIL (Mark Drela 2-D airfoil analysis software), are presented.

The geometry parameters of the RR3823HL airfoil are the following:

- max. Thickness: $8.35 \%$

- max. Thickness chord position: $22.54 \%$

- max. Camber: $3.38 \%$

- max. Camber chord position: $39.12 \%$

The forward positions of the camber and thickness should promote an early transition for high angles of attack and so reduce the pressure drag induced by the LSB.

To carry out the aerodynamic and infrared measurements on the airfoil two wing sections have been realized. Each section is composed by two fibre glassed halves obtained by two moulds; the moulds have been realized by an electronically controlled cutting machine. In the section devoted to the infrared measurements an insulating foam has been used to fill the interior of the wing. An aluminium sheet, $25 \mu \mathrm{m}$ thickness, has been glued on the external wing surface and successively coloured with an high infrared emissivity paint (0.97). A low voltage/high current supply system is used to realize a constant heat flux boundary condition on the aluminium sheet of the airfoil, i.e. the heatedthin-foil technique early used by other authors.

Aerodynamic airfoil measurements have been obtained by a strain gage 6 -axis load balance and turbulence distribution in the wind tunnel test section has been measured by hot wire anemometry.

\section{Results}

\subsection{Aerodynamic results}

The airfoil drag and lift have been measured for a Reynolds number ranging from $60 \mathrm{k}$ to $200 \mathrm{k}$; a typical result at the latter value is reported in Fig.2 with the 2- $\sigma$ deviation distribution.

The drag abruptly increases for moderate angle of attack, this is due to the LSB pressure drag contribution; the stall behaviour of this airfoil seems good, a "large bubble stall" characteristic is shown, probably due to the early transition promoted at high angle of attack. The infrared measurements have confirmed this suggestion. 


\subsection{Numerical and analytical results}

A numerical airfoil analysis has been implemented by using a software package: XFOIL. At the same time an analytical study of the developing laminar boundary layer has been performed by using an integral approach at the boundary layer equation. For the boundary layer velocity profiles a polynomial distribution based on the $1^{\text {th }}$ shape factor, $\Lambda$, has been used to modify the shape of the velocity profile [2]. The separation point position is found with the " $\Lambda=-12$ " criterion. The comparison between inviscid and viscous results has reported in Fig. 3 , for an angle of attack where the drag is moderate. A "plateau" is clearly shown in the viscous pressure distribution and the LSB characteristic points are pointed out in the figure. The transition points have been obtained by two different criterions:

- Horton-Van Ingen based on the Re 2 value in the separation point [3]

- The en criterion (for $n=9$ ) based on the value of the amplification factor [5].

The reattachment point is reached when the inviscid and viscous pressure distributions show the same pattern.

\subsection{Thermographic results}

In Fig.4 the thermographic images of the airfoil for $\mathrm{Re}=200 \mathrm{k}$ and for different angles of attack are reported. Each image has been obtained averaging 50 frames at $8 \mathrm{~Hz}$ sampling rate.

For each angle of attack the "zero-time image" with the wind tunnel switched-off has been stored so as to verify the uniformity of the heat flux distribution on the airfoil surface. To obtain the local convection heat transfer coefficient a finite differences scheme has been used to perform an energy balance on each surface point; finally, a streamwise Stanton number is reported for central line of the airfoil for different angles of attack, see Fig.5.

The infrared images collection reported in Fig. 4 clearly shows the LSB, for angle lower than $-1^{\circ}$ the bubble phenomenon is not visible. A long bubble is shown at greater angles and its start position moves upwind continuously for a increasing; at same time the bubble reduces its dimension. For angles greater than $8^{\circ}$ no bubble is visible. By image observation is very difficult to locate the separation, transition and reattachment points, but by the analysis of the local Stanton number, superimposed with the thermal distribution (Fig.6), is possible to find out the characteristic points:

- a minimum occurs in the Stanton number distribution in the transition point

- the reattachment point is identified by the following peak

- the separation point is placed where an inflection is shown in the Stanton distribution. To carry out the location of the inflection point a cubic regression has been used in a limited range of the thermal data.

\section{Results comparison}

A very good agreement is shown by the comparison reported in Tab.1, where the values are dimensionless ( the streamwise coordinate/airfoil chord length). The Horton criterion identifies a range for the transition since the position point is carried out by the following empirical formulation:

$$
\frac{L_{T}}{\left.\delta_{2}\right|_{\text {separation }}}=\frac{C \cdot 10^{4}}{\left.\operatorname{Re}_{\delta 2}\right|_{\text {separation }}} \quad 3 \leq C \leq 5
$$

for this reason in the table these results are reported as [3]min e [3]max. 
Table 1: Comparison between numerical and experimental results

\begin{tabular}{|c|c|l|l|l|l|l|l|l|l|l|}
\hline \multirow{2}{*}{$\begin{array}{l}\text { Attack } \\
\text { angle }\end{array}$} & \multicolumn{3}{|c|}{ Separation point } & \multicolumn{4}{|c|}{ Transition point } & \multicolumn{2}{c|}{ Reattach. point } & \multicolumn{2}{c|}{ Bubble lenght } \\
\cline { 2 - 11 } & {$[2]$} & \multicolumn{1}{|c|}{ IR } & {$[3]$ min. } & {$[3]$ max. } & {$[5]$} & IR & XFOIL & IR & Num. & IR \\
\hline-2 & Unsep. & Unsep. & ----- & ----- & 0.95 & 0.90 & ----- & ---- & ----- & ---- \\
\hline-1 & 0.52 & 0.50 & 0.64 & 0.73 & 0.88 & 0.74 & ----- & 0.92 & ----- & 0.42 \\
\hline 0 & 0.37 & 0.33 & 0.49 & 0.57 & 0.71 & 0.61 & 0.78 & 0.88 & 0.41 & 0.55 \\
\hline 1 & 0.34 & 0.29 & 0.46 & 0.53 & 0.62 & 0.52 & 0.79 & 0.77 & 0.45 & 0.48 \\
\hline 2 & 0.32 & 0.25 & 0.44 & 0.51 & 0.53 & 0.47 & 0.76 & 0.70 & 0.44 & 0.45 \\
\hline 3 & 0.29 & 0.26 & 0.40 & 0.48 & 0.48 & 0.42 & 0.68 & 0.65 & 0.39 & 0.39 \\
\hline 4 & 0.26 & 0.27 & 0.36 & 0.44 & 0.44 & 0.36 & 0.58 & 0.58 & 0.32 & 0.31 \\
\hline 5 & 0.23 & 0.21 & 0.34 & 0.41 & 0.40 & 0.32 & 0.56 & 0.53 & 0.33 & 0.31 \\
\hline 6 & 0.20 & 0.18 & 0.30 & 0.37 & 0.36 & 0.29 & 0.53 & 0.50 & 0.33 & 0.32 \\
\hline 7 & 0.17 & 0.14 & 0.27 & 0.34 & 0.29 & 0.22 & 0.46 & 0.44 & 0.29 & 0.30 \\
\hline
\end{tabular}

\section{Nomenclature}

$\begin{array}{ll}\mathrm{C} & \text { Airfoil chord lenght } \\ \mathrm{Cd} & \text { Drag coefficient } \\ \mathrm{Cl} & \text { Lift coefficient } \\ \mathrm{Cp} & \text { Pressure coefficient } \\ \mathrm{h} & \text { Convective heat transfer coefficient } \\ \mathrm{H}_{\mathrm{T}} & \text { Bubble height } \\ \mathrm{Gree} & \text { Symbols } \\ \alpha & \text { Angle of attack } \\ \delta & \text { kinetic boundary layer thickness } \\ \delta_{1} & \text { displacement thickness }\end{array}$

\author{
$\mathrm{L}_{\mathrm{T}} \quad$ Bubble transition length \\ $\mathrm{Nu}_{\mathrm{x}} \quad$ Local Nusselt Number \\ $\mathrm{Re}_{\mathrm{x}} \quad$ Local Reynolds Number \\ $\mathrm{Pr} \quad$ Prandtl Number \\ St $=\mathrm{Nu}_{\mathrm{x}} /\left(\operatorname{Re}_{\mathrm{x}}{ }^{*} \mathrm{Pr}\right) \quad$ Local Stanton number \\ $\mathrm{U} \quad$ External boundary velocity \\ $\delta_{2} \quad$ momentum thickness \\ $\Lambda=\left(\delta^{2} / v\right)^{*} \mathrm{dU} / \mathrm{dx} \quad 1^{\text {th }}$ shape factor \\ $v \quad$ kinematic viscosity $\left(\mathrm{m}^{2} / \mathrm{sec}\right)$
}

\section{REFERENCES}

[1] FALKNER, V.M., SKAN, S.W., "Some approximate solutions of the boundary layer equations ", Phil. Mag., 12, 1931, p.865-896

[2] von KARMAN, Th., "Uber laminare und turbulente Reibung", NACA 1092,1946

[3] HORTON, H.P., "A semi-empirical theory of the growth and bursting of laminar separation bubbles ", Aero. Res. Counc., 107, 1967

[4] VAN INGEN, J.L., "On the calculation of laminar separation bubbles in twodimensional incompressible flow ", AGARD Conf. Proc. Flow Separation, 168, 1975

[5] SMITH, A.M.O., and GAMBERONI, N., "Transition, Pressure gradient and Stability Theory", Douglas Aircraft Co., Rept. ES26388, 1956

[6] VAN INGEN, J.L., "A suggested semi-empirical method for the calculation of the boundary layer transition region ", Delft Univ. of Tech., Dept. of Aerosp. Eng., Rept. VTH-74, 1956

[7] SWAFFORD, T.W., "Analytical approximation of two-dimensional separated turbulent boundary layer velocity profiles ", AIAA Jou., 21, 1983, p.923-926 
[8] MANGALAM, S., MEYERS, J.F., DAGENHART, J.R., HARVEY, W.D., "A study of laminar separation bubble in the concave region of an airfoil using laser velocimetry", Symp. On Laser Velocimetry, ASME Annual Meeting, 1985, Miami-Florida (USA)

[9] HAMMOND, D.A., REDEKOPP L.G., "Local and global instability properties of separation bubbles", Eur. J. Mech, B/Fluids, 17 n.2, 1998, p.145-164

[10] LANG, M., MARXEN, O., RIST, U., WAGNER, S., "Experimental and numerical investigations on transition in a laminar separation bubble", NNFM, 77, 2001, p.194201

[11] HAGGMARK, C.P., HILDINGS, C., HENNINGSON, D.S., "A numerical and experimental study of a transitional separation bubble ", Aerosp. Sci. Technol., 5, 2001, p.317-328

[12] LANG., M.,RIST, U., WAGNER, S., "Investigation on disturbance amplification in a laminar separation bubble by means of LDA and PIV ", Proc. $11^{\text {th }}$ Symp. Appl. Laser Tech. Fluid. Mech., 8.-11, 2002, Lisbon, Portugal

[13] ASTARITA, T., CARDONE G., CARLOMAGNO G.M., MEOLA, C., "A survey on infrared thermography for convective heat transfer ", Optics \& Laser Technology, 32, 2000, p.593-610

[14] CESINI, G., MONTELPARE, S., RICCI, R., ZAZZINI, P., "Un metodo termografico per lo studio del fenomeno di separazione dello strato limite laminare in corpi operanti a basso numero di Reynolds", 56 Cong. Naz. ATI, Naples, 2001.

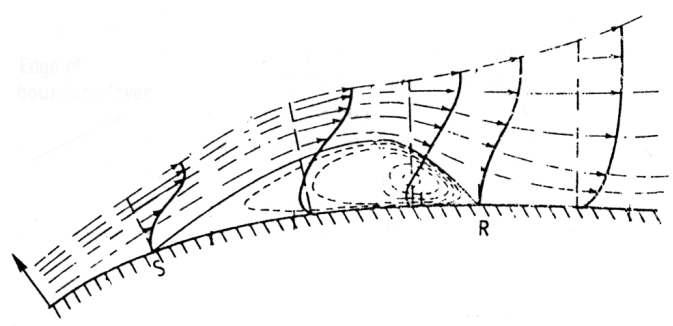

Fig. 1. Sketch of the $L S B$
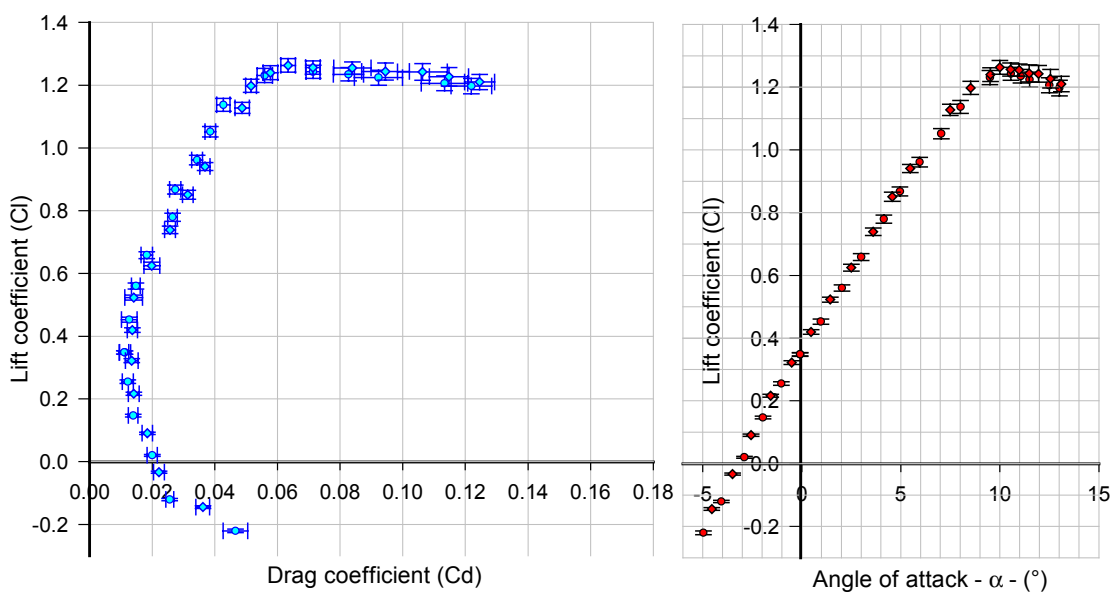

Fig. 2. Aerodynamic measurements of the RR3823HL $(R e=200 k)$ 


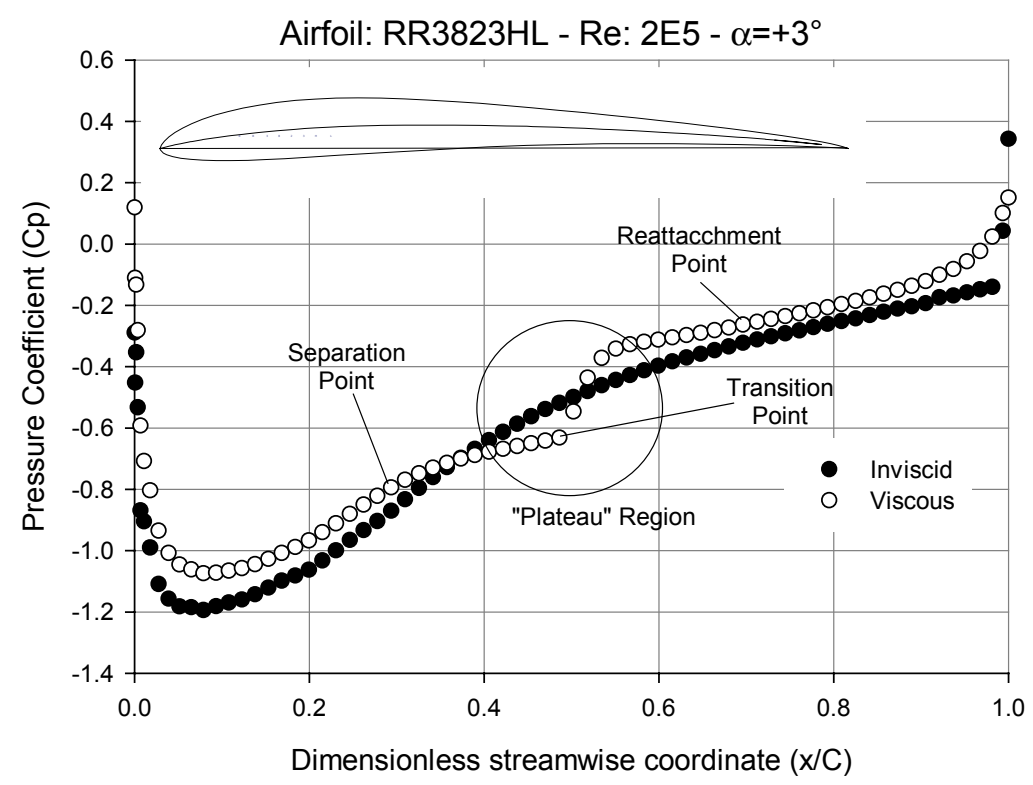

Fig. 3. Pressure distribution on the upper surface of the RR3823HL airfoil

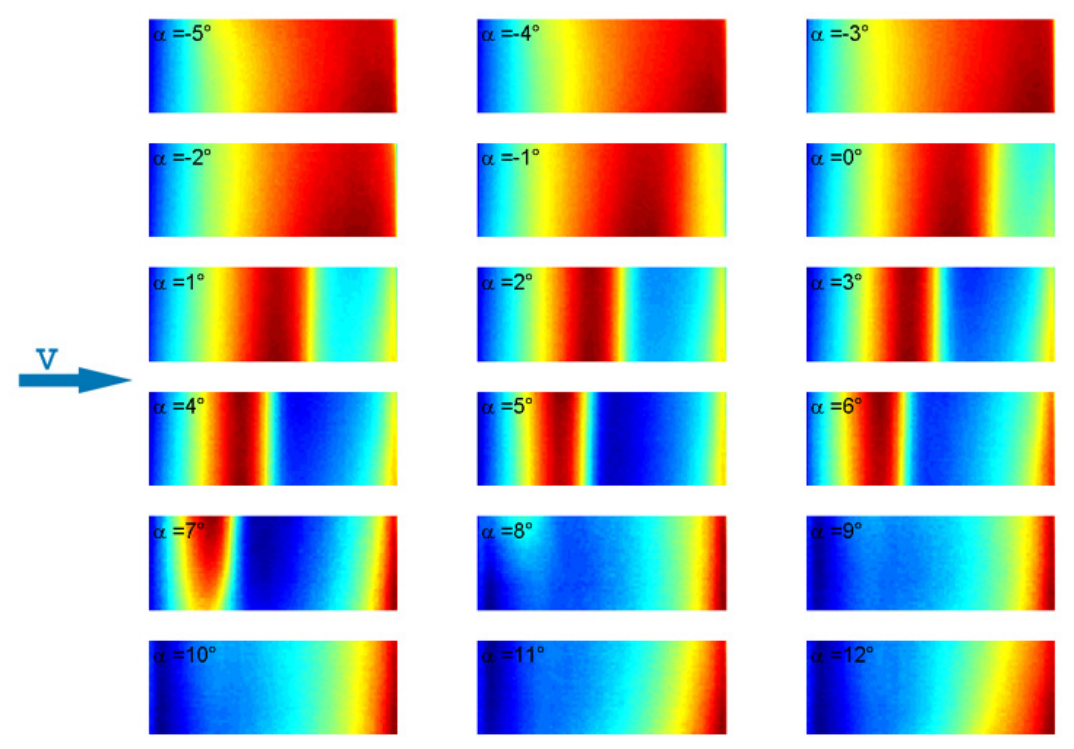

Fig. 4. Infrared images of the upper surface of the RR3823HL for many angles of attack 
http://dx.doi.org/10.21611/qirt.2002.011

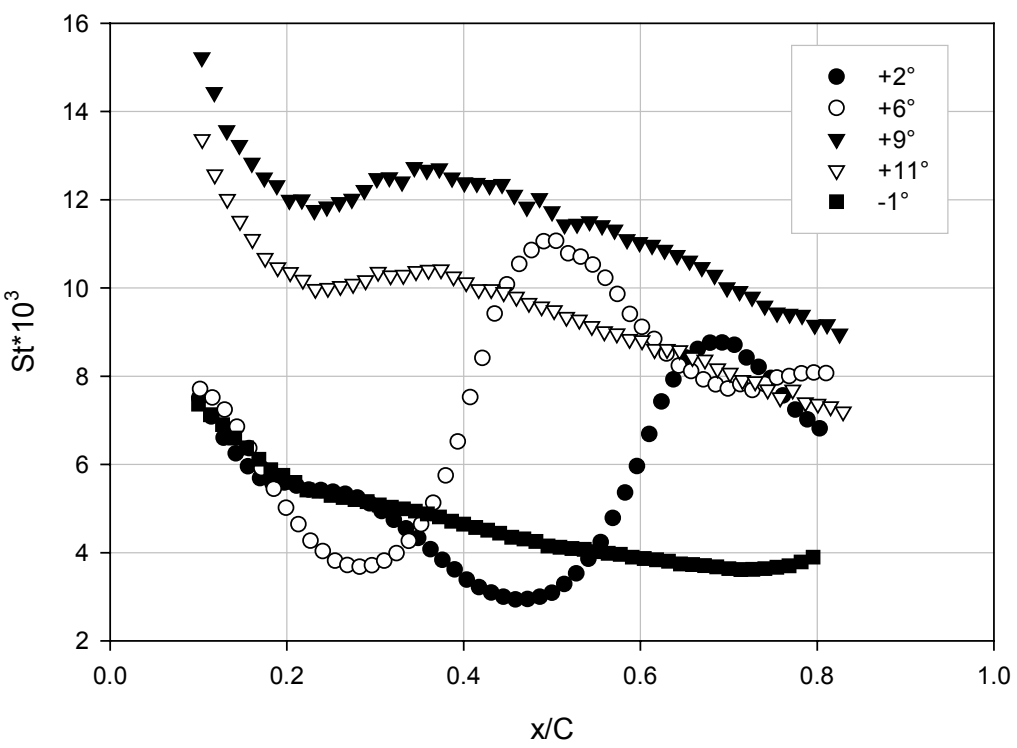

Fig. 5. Stanton Number of the upper surface of the RR3823HL (Re=200k)

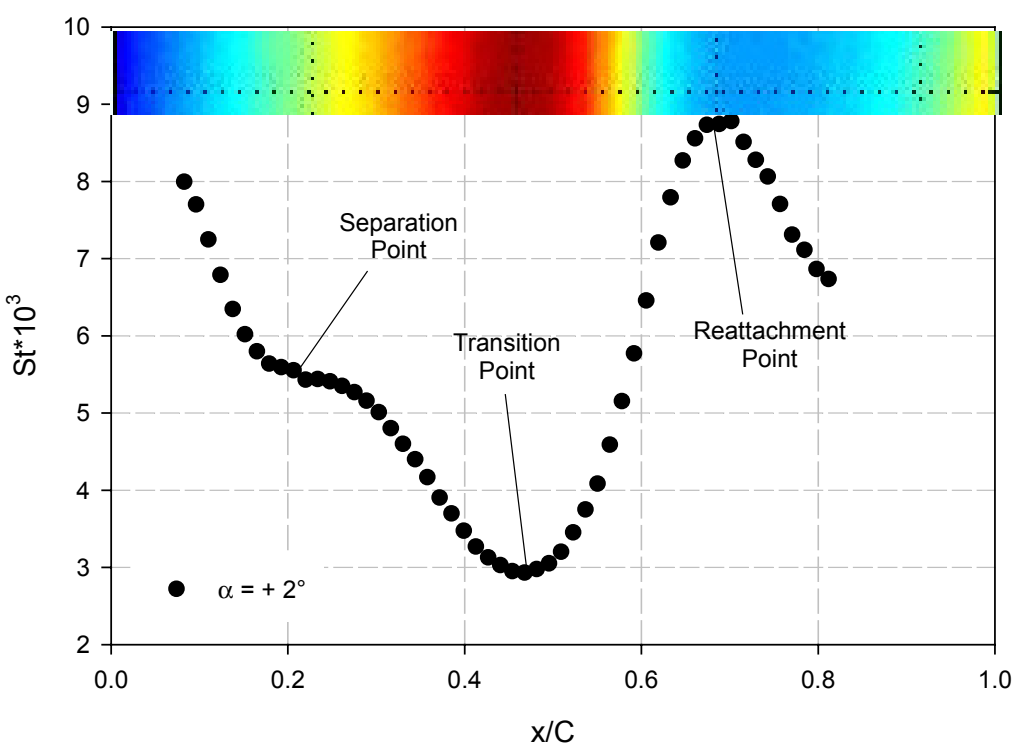

Fig. 6. LSB Characteristic points in the Stanton distribution 